\title{
Satellite SAR Remote Sensing in Nasca
}

\author{
Francesca Cigna and Deodato Tapete \\ F. Cigna $\cdot$ D. Tapete \\ Natural Environment Research Council, British Geological Survey \\ Keyworth, Nottingham, United Kingdom \\ e-mail: fcigna@bgs.ac.uk; deodato@bgs.ac.uk
}

\begin{abstract}
In 2012, a research project initiated at the British Geological Survey used space-borne Synthetic Aperture Radar (SAR) imagery to investigate the environmental changes affecting the drainage basin of Rio Grande and its tributaries, in Southern Peru. Our research has provided evidence of the effects due to natural and anthropogenic processes on the cultural landscape where the Nasca Civilization flourished centuries ago. This chapter provides an overview of the new insights brought by satellite SAR technology to the understanding of land use and changes in the fertile river valleys, condition of local water resources, and archaeological heritage. Impacts of this research are discussed in relation to the rejuvenation of the water supply system and preservation of cultural identity.
\end{abstract}

\subsection{SAR in Nasca}

As widely described in previous chapters of this book, the catchment area of Rio Grande in Southern Peru was the home of the Nasca Civilization (Fig. 21.1), with evidence of human occupation since 2,000 BC, that was concentrated mostly along its tributaries Rio Ingenio, Rio Nazca, and Rio Taruga. After several millennia, local communities still reside and cultivate the alluvial valleys, and their subsistence depends on the available soil and water resources. A longstanding connection therefore exists between the environment and local population, and exposure to climate and natural processes needs to be accounted for in the perspective of maintaining this equilibrium.

Historically, the region was repeatedly impacted by flash floods and run-off of sandy materials from unstable slopes. Archaeological stratigraphic evidence testifies that in $\mathrm{AD} 400-450$ the Ceremonial Centre of Cahuachi declined due to a series of mudslides and severe earthquakes (Tapete et al. 2013).

More recently, the scientific community has started debating whether climate events such as El Niño can be considered among the natural threats affecting the Peruvian dry valleys and, if so, how we can measure their impacts (Lefort et al. 2004). 
In this context, Synthetic Aperture Radar (SAR) data from space have been increasingly accessed by researchers to retrieve surface evidence related to natural surface processes such as soil erosion and degradation (Lefort et al. 2004). It is well known that one of the advantages of SAR is the wide availability of historical datasets, such as the ERS-1/2 and ENVISAT catalogues of the European Space Agency (ESA), providing C-band (4-8 GHz) images that were acquired almost uninterruptedly from 1991 to 2012. In particular, the historical coverage over Nasca (Fig. 21.1) enabled us to source a consistent data stack over the years, with spatial resolution of 25-30 m and swaths of $100 \mathrm{~km}$. These data are suitable for wide-area and regional assessments to identify trends of change or stability, alongside investigation of sites as wholes and contextualized within their surrounding environments. To this purpose, our research project focussed on a retrospective investigation of the regional to local-scale changes due to both natural hazards (mass movements and flooding) and anthropogenic activities (agriculture and archaeological looting).

For local-scale assessment, our research also benefitted from the availability of X-band $(8-12.5 \mathrm{GHz})$ images acquired by the German Aerospace Center (DLR) TerraSAR-X mission since 2008. The range of spatial resolutions varying from 16 $\mathrm{m}$ to $1 \mathrm{~m}$ and scene size from $100 \mathrm{~km}$ (width) by $150 \mathrm{~km}$ (length; extendable to $1,650 \mathrm{~km}$ ) in ScanSAR (SC) mode to $5-10 \mathrm{~km}$ (width) by $5 \mathrm{~km}$ (length) in High Resolution SpotLight (HS) represented a technical improvement with respect to ERS-1/2 and ENVISAT medium-resolution imagery for the detection and delineation of subtle features spread across the landscape including the famous UNESCO World Heritage List geoglyphs of Nasca (Lines and Geoglyphs of Nasca and Pampas de Jumana).

Technique-wise, the region of Nasca was studied by means of interferometric coherence (Ruescas et al. 2009) and analysis of its spatial variation at the microand meso-relief scale (Baade and Schmullius 2010). Our project provided an occasion to develop a methodological approach to the quantitative assessment of radar backscatter variations to investigate land use, soil moisture, and morphological changes (Cigna et al. 2013) and to demonstrate the potential for operational use to detect and monitor archaeological looting (Tapete et al. 2013).

\subsection{SAR Input Data and Processing}

SAR stacks from the archive of the European Space Agency (ESA) were accessed and exploited in the framework of Category-1 project Id.11073 to cover the whole natural and cultural landscape of the Nasca region (Fig. 21.1). These sets included: eight ENVISAT Advanced SAR (ASAR) IS2 scenes acquired along descending orbits between 04/02/2003 and 15/11/2005; and five ENVISAT ASAR IS2 scenes acquired along ascending orbits between 24/07/2005 and 11/11/2007. 


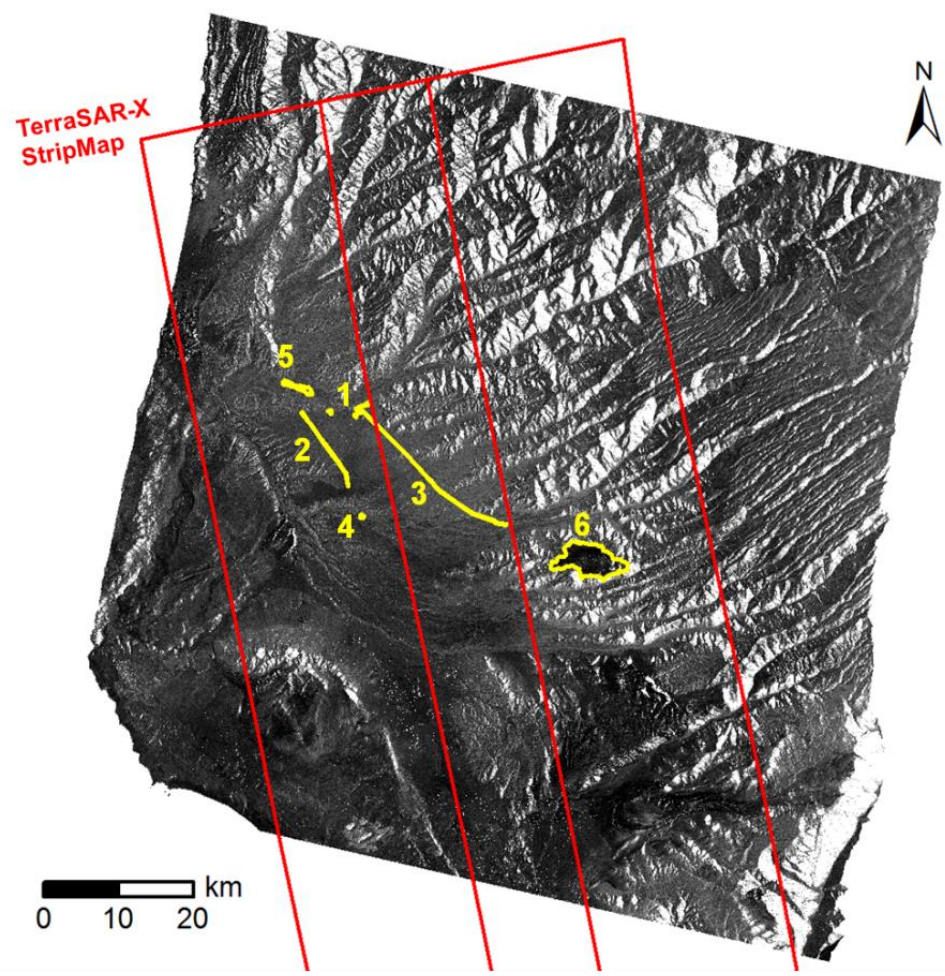

Fig. 21.1 ENVISAT ASAR IS2 image acquired in descending mode on 15/11/2005 and covering the Nasca region, Southern Peru, with 2012 TerraSAR-X StripMap footprints in ascending mode and indication of areas of interest: (1-2) Nazca Lines; (3) Panamericana Sur road; (4) Cahuachi; (5) Rio Ingenio valley and agricultural fields; (6) Cerro Blanco sacred mountain

SAR-based results were also integrated and cross-validated with multispectral Advanced Spaceborne Thermal Emission and Reflection Radiometer (ASTER) data acquired on 30/05/2003, 01/06/2004, and 10/06/2007 in the visible-nearinfrared (VNIR), shortwave infrared (SWIR), and thermal infrared (TIR), with spatial resolutions of 15,30 and $90 \mathrm{~m}$ respectively, and the derived Normalized Difference Vegetation Index (NDVI) and Water Index (NDWI).

For the multi-scale observation of the Nazca Lines, we analyzed the following $\mathrm{X}$-band TerraSAR-X and TanDEM-X images: (i) ScanSAR, HH polarization, ascending mode, range resolution 17.0-19.2 m; (ii) StripMap, HH polarization, ascending mode, range resolution 3.3-3.5 m (Fig. 21.1); (iii) SpotLight, VV and $\mathrm{HH}$ polarization, ascending and descending mode, range resolution $1.7-3.5 \mathrm{~m}$; and (iv) High Resolution SpotLight, $\mathrm{HH}$ polarization, descending mode, range resolution 1.1.-3.5 m.

These images were accessed via the TSX-Archive-2012 LAN1881 project with DLR. 
We mainly exploited the amplitude information to investigate the spatial and temporal changes of the backscattering coefficient $\sigma^{0}$. This indicates the radar signal backscattered to the sensor, normalized-to a first approximation-to the horizontal ground surface and referred to as per unit area on the ground.

The workflow to extract $\sigma^{0}$ values from raw SAR data and convert these to decibel $(\mathrm{dB})$ and multi-temporal change detection analysis is described in Cigna et al. (2013). Nevertheless, it is worth mentioning here how ratios between SAR pairs are computed, as they are the basis for our interpretation of the recent environmental changes we observed across the Nasca region. Two SAR images $k$ and $j$, acquired by using the same acquisition mode and geometry at the times $t_{k}$ and $t_{j}$ respectively, are spatially filtered to reduce the effects of radar speckle and increase the signal content of the image pixels. Their backscatter ratio $\left(R_{\sigma 0}\right)$ is then computed, pixel by pixel, as follows:

$R_{\sigma_{i}^{0}}=\frac{\sigma_{i}^{0}\left(t_{k}\right)}{\sigma_{i}^{0}\left(t_{j}\right)}$

$\mathrm{R}$ is dimensionless and takes on values between zero and one when the considered pixel $i$ has a higher backscattering coefficient at time $t_{j}$ with respect to time $t_{k}$, while values exceeding one occur when the pixel $i$ has lower backscattering coefficient at the time $t_{j}$ with respect to time $t_{k}$.

The result is a map showing the spatial patterns of $\sigma^{0}$ increase and decrease (Sect. 21.3) that can be correlated to changes in soil moisture content, vegetation coverage, or morphology (Cigna et al. 2013), the latter being for instance due to legal or illegal excavations Sect. 21.5).

We also exploited multi-temporal coherence. Coherence $(\gamma)$ is a measure of interferometric phase correlation, and can be computed as the cross-correlation coefficient of two SAR images. This is estimated over a small window of a few pixels in range and azimuth, once all the deterministic phase components (mainly due to the terrain elevation) are compensated for. Computation of the absolute value of $\gamma$, using a moving window over the whole SAR image, results in a coherence map of the observed scene, where values can range from zero to one, i.e., from no correlation to perfect correlation. Strong coherence means high homogeneity with no change of land surface properties or geometric conditions, while low $\gamma$ values are found over altered surfaces. As demonstrated in Sect. 21.3.1, the patterns found in the multi-interferometric coherence map can complement those retrieved based on amplitude change detection. 


\subsection{Regional-Scale Environmental Assessment}

\subsubsection{Land Use and Soil-Moisture Changes}

A demonstration of how valuable SAR can be to track environmental impact due to agricultural activities is here reported with regard to the floodplain of Rio Ingenio, on both yearly and seasonal bases (Fig. 21.2).

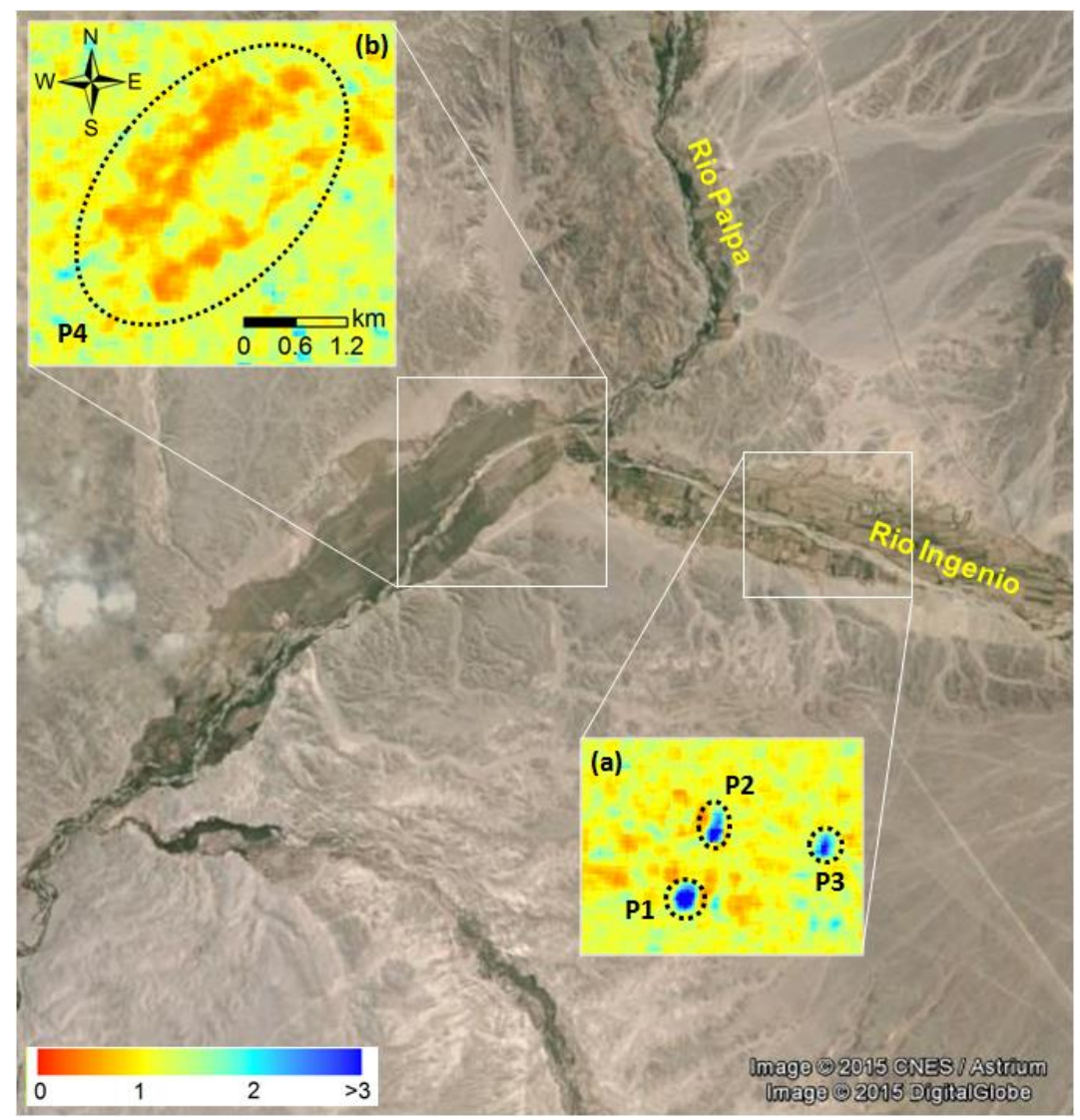

Fig. 21.2 Optical image of the floodplain of Rio Ingenio from Google Earth (C) 2015 CNES/Astrium/DigitalGlobe) with amplitude change detection maps by ratioing the backscattering coefficient $\left(\mathrm{R}_{\sigma 0}\right)$ in: (a) November 2004 and November 2005 (yearly basis), and (b) May 2005 and November 2005 (intra-year assessment). Blue areas indicate increased backscatter (e.g., P1, P2, P3) likely due to an increase in soil moisture between 2004 and 2005, while the red-orange areas (e.g., P4) indicate a decrease in the backscatter from May to November 2005 
Two ENVISAT scenes acquired during the same month of two consecutive years (November 2004 and 2005) were compared to detect changes over one year, and amplitude change was detected (Fig. 21.2a). While orange to dark red areas over agricultural fields indicate a decreased backscatter from 2004 to 2005, three localized areas in blue show $\sigma^{0}$ increase up to $4-5$ times the initial values (P1-P3 in Fig. 21.2a).

ASTER images acquired in June 2003 and 2004 highlight a general decrease in the reflectance in the NIR band and the vegetation cover over the eastern part of this area, even where increased backscattering is found.

On the other side, the ratio November-May 2005 (Fig. 21.2b) shows the difference in backscatter recorded between two opposite seasons. Decrease of $\sigma^{0}$ is apparent in agricultural areas to the west (P4).

The lower radar backscatter is probably due to an overall decrease of soil moisture and possibly to an associated decrease of vegetation, which correspond to a decrease in the reflectivity of the observed ground surface (Cigna et al. 2013). This suggests that variations of radar backscatter could be used as an indicator of land surface changes (vegetation and soil moisture) due to the agricultural cycle. Further analysis of environmental monitoring data could confirm this hypothesis. In the perspective of a regular and repeated monitoring, such a baseline mapping helps to enhance anomalies of radar backscatter.

Unlikely to be associated with human activities of seasonal or yearly frequency, these anomalies might also appear in situations of flooding events, unexpected alteration due to land-use or land-cover change or, in some circumstances, surface indicators of buried features (e.g., anthropogenic or paleochannels).

As mentioned in Sect. 21.1, regional-scale assessment based on amplitude change detection maps can be complemented with corresponding multi-temporal interferometric coherence analyses.

Fig. 21.3 shows $R_{\sigma 0}$ patterns observed between 2005 and 2007 in association with loss of coherence in the floodplain of Rio Nazca, Peru, in proximity to the ceremonial center of Cahuachi. As discussed earlier in this book, the whole area was affected by flood events to the extent that the settlements were heavily damaged or destroyed. Although the river brings fresh mud yearly and creates a fertile strip for agriculture, it still represents a potential treat for the local archaeological heritage, which could be damaged by floods due to extreme weather conditions, also in relation to El Niño. Alteration of the radar backscatter between dry, wet, and flooded un-vegetated surfaces can therefore be also used to infer the impact in the recent past and assess flood hazard and susceptibility.

In addition to their scientific value, the findings of this research may generate impacts for the benefit of the local community and natural environment. The retrospective analysis we have undertaken with ENVISAT suggests that radar backscatter can be used as a proxy to measure and spatio-temporally contextualize the anthropogenic impact on the landscape in Nasca, and that there is scope to extend this type of monitoring. Therefore, the observed patterns not only represent 
the basis that future change detection analyses of more updated SAR data should be compared with, but also may encourage local authorities to review the current practice of land management, as they suggest where major changes of soil properties and land use occurred in recent years.
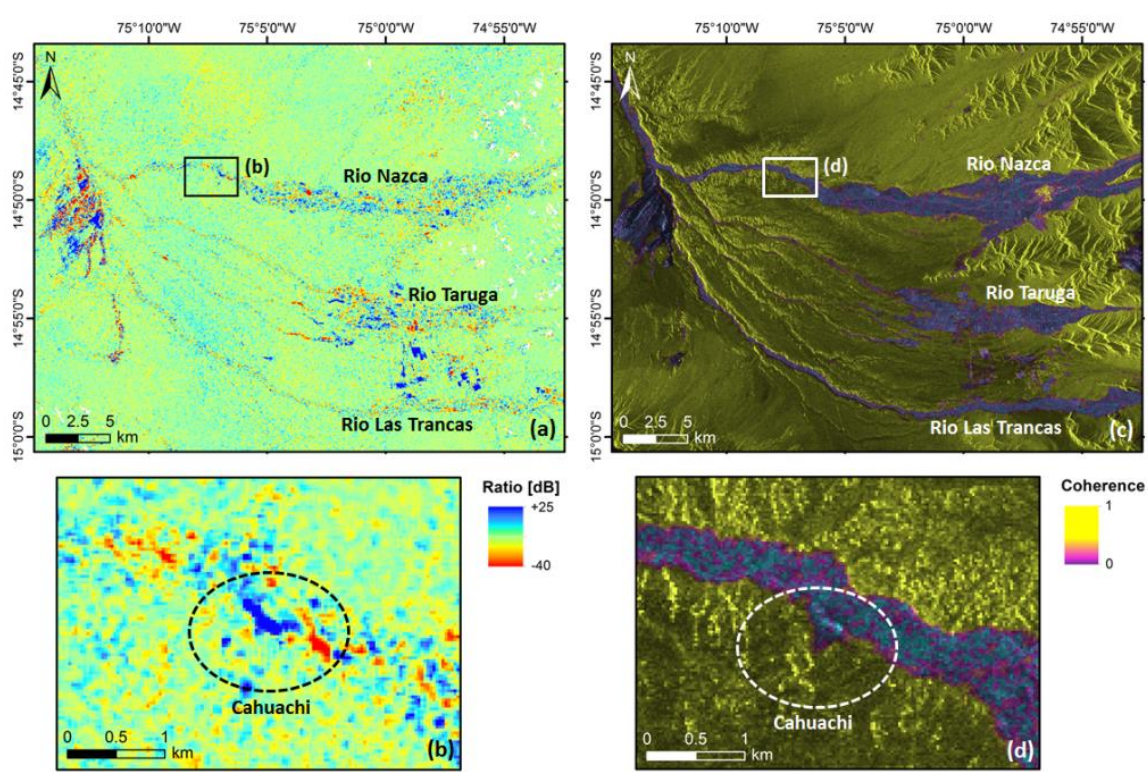

Fig. 21.3 Change detection maps based on $(\mathbf{a}-\mathbf{b})$ the ratio of the backscattering coefficient between ENVISAT ascending mode images acquired on 2 February 2005 and 7 October 2007, and (c-d) the corresponding coherence maps (Bperp $4 \mathrm{~m}$ ) over the Nasca Civilization region in Peru and the archaeological site of Cahuachi (Tapete and Cigna 2016). The dotted circles highlight areas where changes in the ratio (blue-red patterns) are associated with loss of coherence (pink-purple patterns) likely due to soil moisture and vegetation changes along the river plain as seen in (a, c) for the Rio Nazca, Taruga and Las Trancas plains, and (b, d) archaeological excavations in the area of the ceremonial centre of Cahuachi

\subsubsection{Monitoring Landforms and Mass Movements}

Wind-driven dynamics of sand-dune displacements and mass movements triggered by sudden rainfall events are common land-surface processes in the arid areas of the Nasca region (Cigna et al. 2013) and might impact the preservation of archaeological features of this cultural landscape.

We tested our approach described in Cigna et al. (2013) to investigate surface evolution of a sand dune area located $30 \mathrm{~km}$ south of Cerro Blanco (a mountain considered sacred by the inhabitants of Cahuachi). Fig. 21.4a shows a multi-year RGB color composite of three ENVISAT scenes acquired on 04/02/2003, 
$30 / 11 / 2004$ and $15 / 11 / 2005$. Green areas are related to greater radar reflectivity in November 2004 while blue and magenta areas indicate higher backscattering in 2003 and 2005, suggesting the occurrence of movements of sandy material that significantly modified the local surface morphology and the related radar backscattering. Comparison with Google Earth imagery clarifies the nature of the processes affecting the sand-dune surface, the morphology of which varies significantly with the season and the year (Fig. 21.4b). This example provides a proof-of-concept of what image analysts and archaeologists can do using regular SAR acquisition to monitor the evolution of natural landforms and prevent potential impacts on archaeological and landscape features nearby.
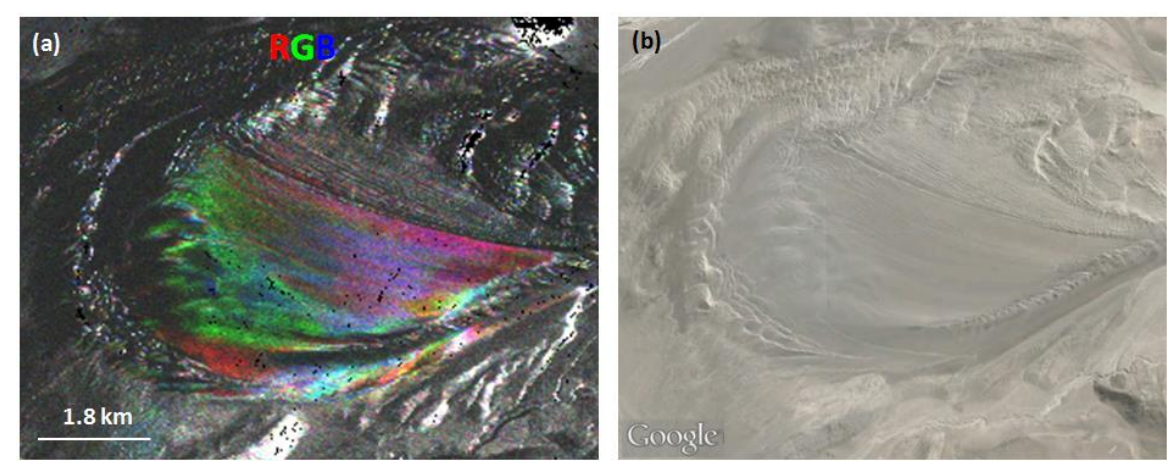

Fig. 21.4. (a) RGB color composite of a sand dune south of Cerro Blanco obtained by comparison of ASAR descending scenes acquired on 04/02/2003, 30/11/2004, and 15/11/2005; and (b) corresponding Google earth (C) 2013 DigitalGlobe)

\subsection{From Natural Environment to Anthropogenic Features}

One of the strongest linkages between the natural environment and the civilizations that populated Nasca is the ensemble of infrastructure built to make this region more liveable. Systems to supply water fall within this category.

Further elements of connection are represented by the religious structures and infrastructure, above all the geoglyphs of Nasca, the function of which is still under debate within the scientific and archaeological communities.

\subsection{1 (Re-)discovering Ancient Water systems: Puquios of Nasca}

Rainfall is very limited on the southern coast of Peru, and rivers in Nasca are affected by water deficiency throughout the year. Therefore, water availability and accessibility are a real constraint in this region. Hydrological conditions in past 
centuries were probably comparable with the present ones, if the inhabitants of Nasca at the time needed to create systems of aqueducts called puquios to store and supply water (Schreiber and Rojas 2006; Lasaponara and Masini 2012).

These horizontal wells exploited the natural topographic gradient to collect water and were typically formed by an open trench and/or a subterranean gallery connecting the surface with the subsurface water (Fig. 21.5). The need to understand these partially or totally hidden structure, and the conservation history by which some of the puquios were abandoned if not even destroyed, now make desirable the development of investigation methods that would enable the (re)discovery of these features from the surface.

From the radar point of view, discrimination of $\sigma^{0}$ properties over the monitored scene can lead to the recognition of morphological features which may be attributed to archaeological remains and traces of ancient puquios. Besides geometry and surface roughness, soil moisture content and material composition also have an effect on radar brightness. This aspect was used to distinguish still functioning puquios from those abandoned in the valley of Rio Taruga belonging to the southern group of tributaries of Rio Grande (Fig. 21.5a; Tapete et al. 2013).

RC color composites of two scenes acquired on 30/11/2004 and 15/11/2005 and ASTER-derived 2003-2004-2007 NDVI and NDWI indices suggest changes of soil moisture and vegetation over a large, dry, hydrographic reticulum lying within the desert between the Rio Nazca and the Pampa de Chauchilla. Among other features, one was found in correspondence with the track of a younger puquio (for further detail, the reader can refer to Tapete et al. 2013, 2014).

The multi-temporal ENVISAT scene over the Taruga Valley enables us to identify the still- functioning puquios Santa María and San Carlos, as well as the disused puquio Camotal. The latter is distinguished based on different $\sigma^{0}$ possibly due to its condition of abandonment (Fig. 21.5b).

The capability of SAR imagery to support the recognition of ancient hydraulic systems opens new perspectives in water resource management from space. Impacts on arid cultural landscapes facing drought can be enormous for local communities. Furthermore, the assessment of the current condition of archaeological features such as the puquios can inform about the potential impacts of climate change and desertification

Among the implications that such research and improved knowledge can generate, it is worth mentioning the possible social and economic benefit to local communities that might be supplied with more water by rejuvenating these past water systems or by building new infrastructure following similar, environmentally sustainable designs. 


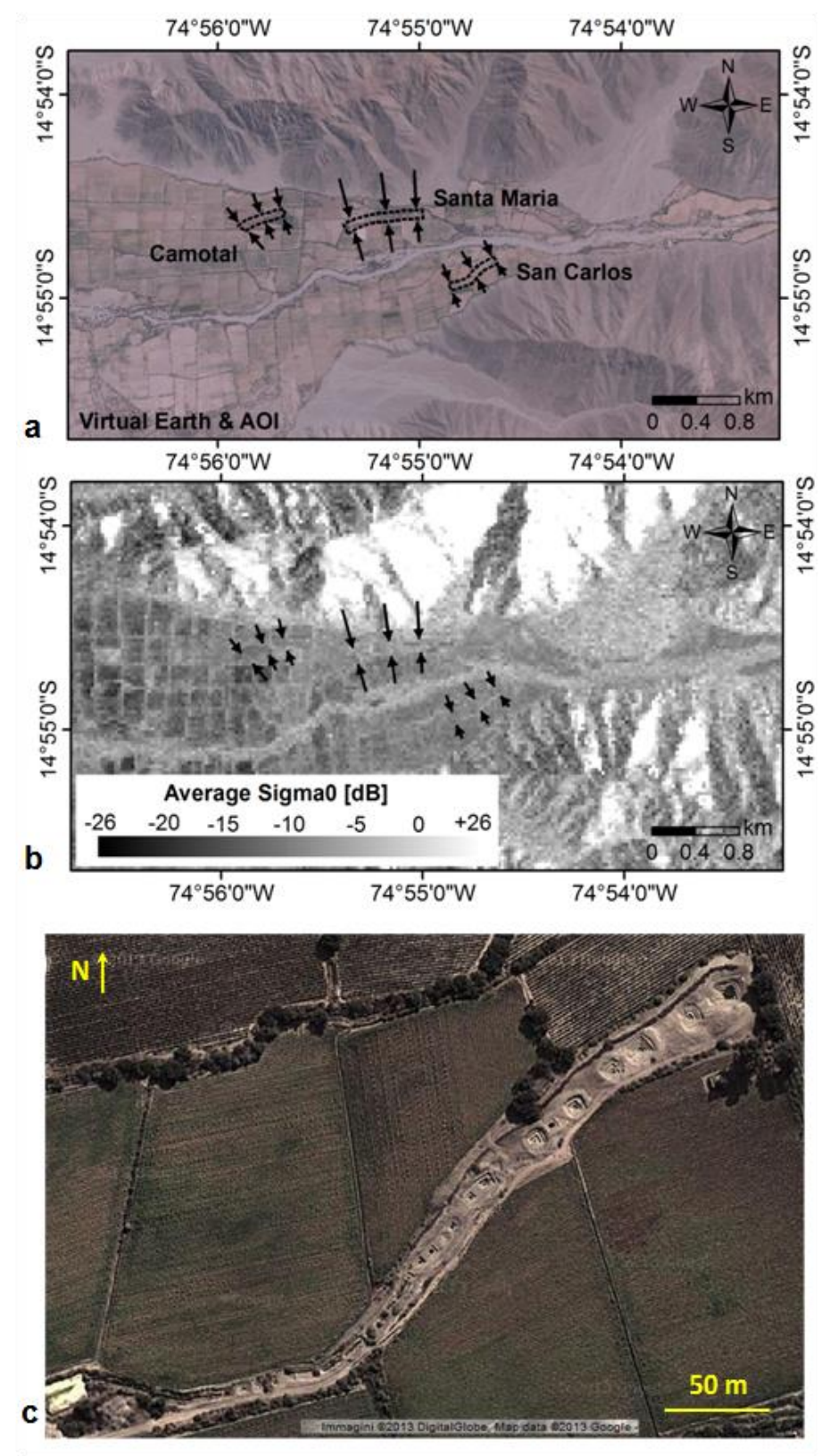

Fig. 21.5 (a) Google Earth image (c) 2015 CNES/Spot Image) and (b) 2003-2005 average ENVISAT scene of Rio Taruga and the three puquios Camotal, Santa María, and San Carlos. (c) Google Maps view of puquio San Carlos (C 2013 DigitalGlobe Map data). Dashed rectangles in (a) and arrows in (a-b) indicate the location of the puquios in the optical and radar data 


\subsubsection{Delineating Subtle Features: Geoglyphs of Nasca}

As mentioned in section 21.1, a multi-scale approach has been tested over the geoglyphs of Nasca located near the Panamericana Sur road (Fig. 21.6).

The full range of beam modes and incidence angles offered by the TerraSAR-X satellite mission proved beneficial in improving the detection and delineation of such subtle archaeological features, while relating them to the landscape over a wide swath. Fig. 21.6 demonstrates the stunning improvement in SAR imaging from ScanSAR to High Resolution Spotlight modes to discriminate the UNESCO World Heritage List Nazca Lines (see also Tapete et al. 2015a).

It is well known that these 'negative geoglyphs' are low-relief drawings made by exposing unpatinated and lighter-colored ground (Cigna et al. 2013). Within SAR images, the geoglyphs typically appear darker compared to the surrounding soil. Such a radar property is evident, even in the images with the lowest resolution (about $17 \mathrm{~m}$; Fig. 21.6b), although the boundaries with the neighboring pixels are expectedly vague and not well defined.

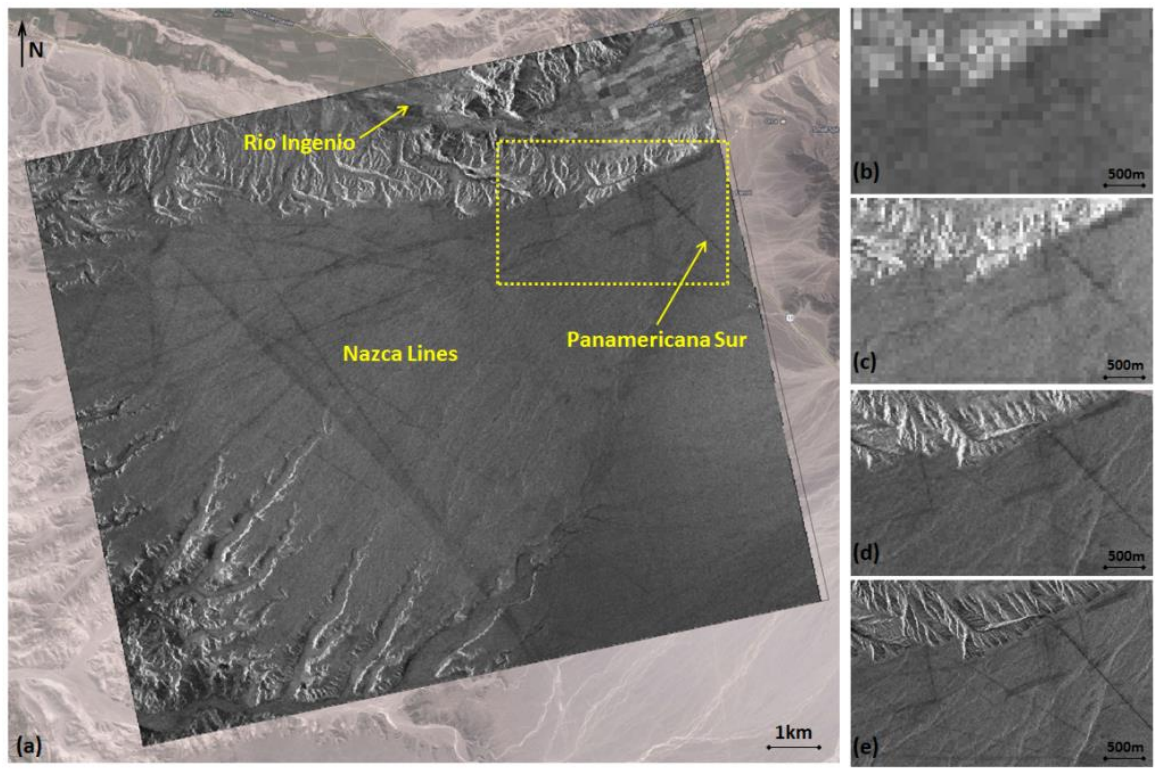

Fig. 21.6. X-band SAR images of the Nazca Lines (Tapete and Cigna 2016): (a) TerraSAR-X SpotLight 13 August 2008 ascending mode with VV polarization, $32.5^{\circ}-33.6^{\circ}$ incidence angles over the Nasca Lines (C DLR 2016), overlapped onto optical imagery (C 2013 Google Imagery (C) Cnes/Spot Image, DigitalGlobe, Map data (C) Google). Comparison of: (b) ScanSAR TerraSAR-X, HH polarization, ascending, range res. 17.0-19.2 m; (c) StripMap TanDEM-X, HH polarization, ascending, range res. 3.3-3.5 m; (d) SpotLight TerraSAR-X, HH polarization, descending, range res. 1.7-3.5 m; (e) High Resolution SpotLight TanDEM-X, HH polarization, descending, range res. 1.1-3.5 mm (C) DLR 2016) 
The distinctive radar signature of the geoglyphs can be analyzed by drawing a backscatter profile from the feature to the nearby soil (darker gravels) and checking its consistency or variations by year or by season. Full descriptions of this method and the outcomes achievable are reported in Tapete et al. (2013).

The improved spatial resolution of the images makes space-borne SAR a useful resource for archaeologists and conservators to complement optical data in assessing the condition of these subtle features.

\subsection{Protection of Archaeological Heritage: Looting in Cahuachi}

Decades of archaeological research in Peru have proved that this region has a wealth of ancient buried remains that, unfortunately, are also the target of looters (refer to previous chapters of this book). Looting manifests in the form of large holes, of meter to decameter size, which destroy irreversibly the archaeological context and its former morphology and appearance.

No attempts to use SAR for detection of looting had been undertaken prior to our project, and probably this technique had been neglected due to the resolution offered by ERS-1/2 SAR and ENVISAT ASAR sensors, compared with optical satellites. Our idea, instead, was that, if $30 \mathrm{~m}$ resolution images were sufficient to detect buried and abandoned puquios, they might also provide surface evidence of changes in radar backscatter as a consequence of morphological alterations due to looting.

With this concept in mind, we performed a multi-temporal analysis to measure $\sigma^{0}$ changes recorded in the ceremonial centre of Cahuachi (Fig. 21.7a).

Looking at the whole period covered by the descending mode data (04 February 2003-15 November 2005), two blue-colored patterns indicate an increase in the radar backscatter over the Pirámide Naranja and the south-eastern corner of Sector B (Fig. 21.7b). These patterns coincide with the adobe structures that were exposed by the archaeological excavations done by the ITACA mission. Thus, the second peak in the 'A-A' ratio profile in Fig. 21.7c relates to authorized archaeological excavations, whereas the first one cannot be attributed to legal excavations. Integration with ground truth and records of archaeological excavations also enabled us to exclude effects of surface erosion or other types of disturbance. Other radar backscatter changes that were observed to the north and west of the center are not related to the ceremonial center but to variations in soil properties (e.g. moisture content) across the river plain.

This type of analysis is a retrospective investigation, at site-scale, of past events of looting and has the added value of evidencing issues of the recent history of the archaeological structures. If applied to newly acquired imagery with higher spatial resolution, this change-detection method could be suitable for operational monitoring of looting on a regular basis, even at the scale of individual structures, as it is currently successfully tested in the Middle East (Tapete et al. 2015b, 2016). 

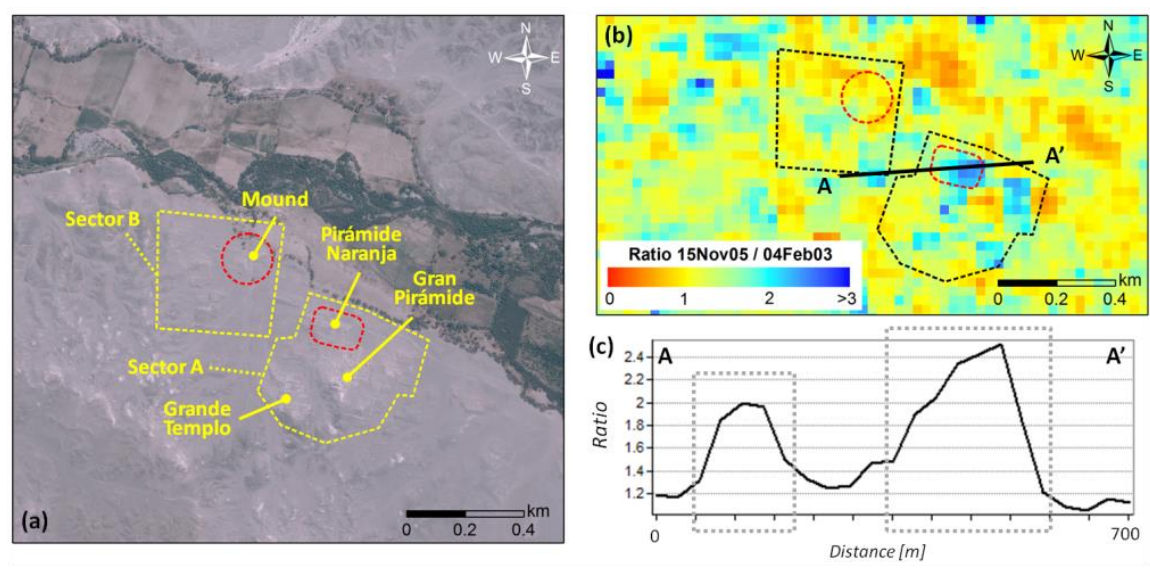

Fig. 21.7. (a) Google Earth image (ㄷ 2015 CNES/Astrium/DigitalGlobe) of Cahuachi Sectors A and $\mathrm{B}$ enclosing archaeological mounds. (b) Corresponding amplitude-change detection map based on $R_{\sigma 0}$ in February 2003-November 2005. (c) A-A' ratio profile. The blue patterns in (b) refer to morphological alterations over the southeast corner of Sector B and Pirámide Naranja

\subsection{Concluding Remarks}

Our satellite studies in Nasca demonstrated that SAR remote sensing and imagery can be exploited to identify changes in surface morphology, soil moisture, and vegetation across this arid region. These data are particularly useful for regional assessment of landscape changes and evolution and to plan further ground investigations and archaeological missions. In this role, information derived from multi-temporal analysis of radar backscatter signals and changes need to be interpreted in relation to land-use changes and management, environmental monitoring data, and the recent history of the sites, including activities of the archaeological missions and, in some cases, illegal excavations by looters.

Acknowledgments This research was initiated and led by Dr. F. Cigna, in collaboration with Dr D. Tapete. ENVISAT ASAR data were made available by the European Space Agency (ESA) through Category-1 project Id.11073 (PI: F. Cigna), and TerraSAR-X and TanDEM-X data from the German Aerospace Center (DLR) via the TSX-Archive-2012 LAN1881 project (PI: D. Tapete). Data processing was carried out using GAMMA SAR and Interferometry Software licensed to the British Geological Survey (BGS), Natural Environment Research Council (NERC). The authors publish with the permission of the Executive Director of BGS, NERC. 


\section{References}

Baade J, Schmullius C (2010) High-resolution mapping of fluvial landform change in arid environments using TerraSAR-X images. In: Geoscience and Remote Sensing Symposium (IGARSS), 2010 IEEE International, p 2159-2162

Cigna F, Tapete D, Lasaponara R, Masini N (2013) Amplitude change detection with Envisat ASAR to image the cultural landscape of the Nasca region, Peru. Archaeol Prospect 20:117131

Lasaponara R, Masini N (2012) Following the Ancient Nasca Puquios from Space, In: Lasaponara R, Masini N (Eds) 2012, Satellite Remote Sensing: a new tool for Archaeology, Springer, Verlag Berlin Heidelberg, p 269-290

Lefort A, Grippa M, Walker N et al (2004) Change detection across the Nasca pampa using spaceborne SAR interferometry. Int J Remote Sens 25:1799-1803

Ruescas AB, Delgado JM, Costantini F et al (2009) Change detection by interferometric coherence in Nasca Lines, Peru (1997-2004). In: Fringe Workshop Proceedings 2009, European Space Agency SP-677, ESA-ESRIN, Frascati, 30 November- 4 December 2009

Schreiber K, Rojas JL (2003) Irrigation and Society in the Peruvian Desert: the Puquios of Nasca. Lexington Books.

Tapete D, Cigna F (2016) Trends and perspectives of space-borne SAR remote sensing for archaeological landscape and cultural heritage applications. Journal of Archaeological Science: Reports, 11 pp. doi: 10.1016/j.jasrep.2016.07.017

Tapete D, Cigna F, Masini N, Lasaponara R (2013) Prospection and Monitoring of the Archaeological Heritage of Nasca, Peru, with ENVISAT ASAR. Archaeol Prospect 20:133147

Tapete D, Cigna F, Lasaponara R et al (2014) Investigating natural hazards in the Peruvian region of Nasca with space-borne radar sensors. In: Sassa K (ed.), Landslide Science for a Safer Geo-Environment - Volume 3, Springer International Publishing Switzerland, p 357 362

Tapete D, Cigna F, Lasaponara R et al (2015a) Multi-scale detection of changing cultural landscapes in Nasca (Peru) through ENVISAT ASAR and TerraSAR-X. In: Lollino G et al (eds), Engineering Geology for Society and Territory - Vol. 8, Springer Int. Publishing, $p$ 339-343

Tapete D, Cigna F, Donoghue DNM (2016) 'Looting marks' in space-borne SAR imagery: Measuring rates of archaeological looting in Apamea (Syria) with TerraSAR-X Staring Spotlight. Remote Sensing of Environment 178:42-58

Tapete D, Cigna F, Donoghue DNM et al (2015b) Mapping changes and damages in areas of conflict: from archive C-band data to new HR X-band imagery, towards the Sentinels. In: Fringe Proc. 2015, European Space Agency SP-731, ESA-ESRIN, Frascati, 23-27 Mar 2015 